\title{
Insights into Components of Prospective Science Teachers' Mental Models and Their Preferred Visual Representations of Atoms
}

\author{
Aysegül Derman ${ }^{1}\left(\mathbb{D},{\text { Nuriye } \text { Koçak }^{1}(\mathbb{D} \text { and Ingo Eilks }}^{2, *} \mathbb{C}\right.$ \\ 1 Department of Elementary Science and Math Education, Ahmet Keleşoğlu Education Faculty, \\ Necmettin Erbakan University, New Meram Str. 132, Konya 42090, Turkey; aderman@erbakan.edu.tr (A.D.); \\ nkocak@erbakan.edu.tr (N.K.) \\ 2 Department of Biology and Chemistry-Institute for Science Education, University of Bremen, \\ Leobener Str. NW2, 28359 Bremen, Germany \\ * Correspondence: ingo.eilks@uni-bremen.de
}

Received: 5 May 2019; Accepted: 14 June 2019; Published: 21 June 2019

\begin{abstract}
This study focused on determining the elements of mental models of atomic structure and views on visual representations of models of atomic structure in two sub-cohorts of student teachers studying at a university in Turkey. In total, 141 student teachers participated in this study. In the first cohort, the focus was on 73 freshman science student teachers' drawings of mental models of atomic structure. The analysis showed a wide variety of individual aspects in the students' minds when asked to sketch the structure of atoms. The majority of students preferred to draw two-dimensional structures, neglecting the atom's space-filling character. Concerning the details of atomic structure, the majority of students emphasized only the most essential components of atoms, namely protons, neutrons, and electrons. It was quickly recognizable that these elements were arranged according to different analogies or representations of historical models, particularly related to Bohr's atomic theory and different representations thereof. Overall, the different visual representations of atomic models the students see in school, almost exclusively serve as the basis for their ideas about atomic structure. Current atomic theory, like quantum mechanical models, are generally not used when students are asked for a "contemporary" model of atoms. Rather it seems that concreteness and functionality are the primary factors leading to the selection of an atomic model when requested. This study is supplemented by data collected from the second cohort of 68 prospective teachers consisting of a diverse group of students ranging from freshman to senior level. The students in this cohort were asked for their preferred illustrations of atoms in textbooks. Open-ended questions about atoms led to further insights. The analysis of the prospective teachers' drawings indicated that a more careful approach to teaching is necessary to clarify the relationships between different models of atomic structure and to allow students to understand what an appropriate and contemporary understanding of atomic structure should encompass.
\end{abstract}

Keywords: prospective science teachers; science education; mental models; atoms; atomic structure

\section{Introduction}

Students form impressions of various topics in their daily lives and in school, through interactions with nature and by communicating with other people about them. Based on these common experiences, students develop mental models of issues pertaining to life and science; for example, personal mental constructs concerning light, force, and the composition and structure of matter. Mental models are used to conceptualize and communicate about a given content, but they also have a large impact on further classroom learning [1-4]. 
There is currently no unanimous agreement on how atomic structure should be taught in schools. Different teachers and faculties employ different strategies, ranging from a coherent approach to the topic, all the way to a set of changing atomic models following the path of their chronological and historical development [5]. As a result, textbook illustrations of atomic models also vary greatly [6], leaving the question wide open as to what specific elements students' mental models of atomic structure actually encompass. This question can be investigated by analyzing the elements that come into the student's mind (and how they are arranged) when the learner is asked to communicate a personal understanding of atomic structure in two ways-through a drawing or through responses to open-ended questions.

Although it might be impossible to obtain a full picture of an individual's mental model on a given topic, insights can be gained by analyzing drawings created in response to the task of sketching one's personal imagination [7]. Further findings could also be obtained by comparing a sketch of a mental model from an individual, with a set of models drawn by a specific group of individuals, e.g., prospective science teachers. This study focused on two groups of prospective science teachers (PSTs) in Turkey. One group comprised 73 Turkish freshman primary student teachers, the second group consisted of 68 randomly chosen primary student teachers from different years of their teacher education program. Both groups of participants represented individuals who have both completed the school science curriculum and intended to become experts in the content matter of chemistry, as well as the communication of chemistry in teaching.

Gunstone and White [8] stated that drawings can be an effective way of revealing natural, high-quality data about hidden thoughts, understandings, and attitudes linked to a given concept. Drawings provide participants with opportunities to freely express their knowledge and beliefs, without the use of words [9]. In light of this, the current study analyzed 73 drawings of Turkish prospective science teachers in response to the instructions: "How do you visualize a contemporary model of the atom in your mind? Please draw it and name each detail on it." The results from this sample was then compared and supported with a second sample of prospective science teachers. The second group was asked to select their most preferred representations of atomic models from a set of typical textbook illustrations. This also involved providing responses to several questions related to their ideas about atoms and their sizes, visibility, and other atomic properties.

\section{Literature Review}

\subsection{The Nature of Mental Models and Their Importance When Learning about Atomic Structure}

In 1992, Vosniadou and Brewer [10] investigated elementary school students' understanding of the Earth, its shape, and the regions where people live. When students were asked about these issues, they often referred to their prior experience and knowledge to create their mental models. Vosniadou [11] stated that mental models "refer to a special kind of mental representation, an analogical representation, which individuals generate during cognitive functioning" (p. 48).

Mental models contain various characteristics. They are generative and synthetic, involve tacit knowledge, and are also restricted by one's worldview [12]. Mental models help individuals give meaning to aspects of the physical world by interpreting information and their experiences [13]. For Norman [14], these models are fundamental descriptions of objects and ideas. According to a constructivist view of learning [15], mental models result from what is actually going on in the learner's mind. They form a personal representation of impressions concerning a certain object or phenomenon. Since mental models occur as a result of individual experience, they are unique. It is hardly possible to reveal a full picture of all of them [13]. However, drawings are one possible approach to get at least an approximate insight into the essential components of mental models, e.g., in the case of atomic structure [6].

Personal feelings and connotations stemming from an instructional design (or some source of information) play a great role in decoding instructional messages and in the construction of a learner's 
mental models. Each individual constructs his or her own mental models. These models are individuals' private cognitive representations and, thus, cannot be predicted [13]. Mental models do not have to be technically precise, but must be functional. Keeping all of this in mind, it could be said that exploring mental models is difficult, abstract and vague in nature, and hard to describe in precise terms. There is also the chance that people might act contrary to their beliefs due to their unwillingness to express them $[14,16]$. Therefore, it is important to keep in mind that explanations based on mental models can only be viewed as interpretations based on personal reception [13]. Nevertheless, educators find it valuable to possess at least a general idea of the similarities and differences of their students' mental models.

\subsection{Teaching and Learning about Atomic Structure}

Visual impressions of chemical structures are mainly fostered in the science classrooms. They are formed on the basis of the teacher's input, the selected curriculum, and the particular textbooks being used $[17,18]$. Additional input comes from the media, be it traditional or digital media, or other informal sources. In order to interpret the non-visible, sub-microscopic representational level of matter [19], teachers and textbook authors are regularly forced to employ analogies, analogical models, and visual representations. The idea is to provide students with a more tangible picture of abstract sub-microscopic concepts like atoms and their structure. It is not fully understood how students' mental models interact with the visual representations presented in textbooks or used by teachers. However, it is generally accepted by most curricula that use of various models and corresponding visual representations in science classes are necessary and beneficial. This is done even though it is equally well-known that the use and representation of models by teachers is not always carried out with sufficient care and attention to possible pitfalls $[20,21]$. Studies on this issue reveal that learners do not always understand analogies and scientific models, as expected. On the contrary, learners often find the various analogies and models too difficult to understand, and even confusing $[3,13,20,22]$. This is quite frequently the case when different historical models are used but not properly related to each other and are not reflected in the foreground of the nature of scientific models. Mixed and hybrid models can emerge and make the learning of the corresponding theory confusing [23].

Coll and Treagust [13] found that learners possess a variety of concepts with regards to the mental models of bonding in ionic substances. The participants generally tended to use simple models [13]. In an interview-based study, Harrison and Treagust [3] tried to investigate 8th-10th grade students' mental models of atoms and molecules and concluded that, pupils generally prefer discrete and concrete models. Although modeling is an important ability in the scientific method, many young science learners find it difficult to differentiate between models and the real world [24]. Textbooks sometimes mix aspects from both domains [21], thereby adding to the confusion. By mixing submicroscopic knowledge of atomic structure with daily-life experiences, for example, researchers found that some students assumed that atoms can reproduce and grow much like biological organisms and that the atomic nuclei can easily break [3]. In a similar vein, Harrison and Treagust [22] kept records of 11th grade students' $(n=10)$ modeling experiences, intellectual development, and conceptual status in their learning process of atoms, molecules, and chemical bonds. They observed that students who used the common analogies, tended to apply the corresponding models more regularly in their explanations. Furthermore, it was noticed that students who used multiple particle models happened to demonstrate a more scientific conceptualization of particles and their interactions, while the other learners failed to focus on the most suitable models. There are also some newer studies that have addressed the learning difficulties and misconceptions related to atomic structure. Çökelez and Dumon [25] did a study to highlight the collectively assimilated knowledge by French upper secondary school students (grades 10 to 12) and identified many different representations and misconceptions related to the concepts of atoms and molecules. Park and Light [26] reviewed a whole range of alternative student mental models of atomic structure, showing that many students have mixed mental models that are based on fragmented pieces of knowledge. They explored the troublesome nature of the atomic structure 
and concluded that certain science concepts cannot be adequately identified only by the experience of experts (e.g., teachers) but needed to be analyzed through the views of the student as well. This was the focus of part of this study, since it tried to inductively analyze the single elements that come into the minds of learners when being asked for a contemporary visual representation of atomic structure.

Papageorgiou et al. [27] investigated the formation of particular student profiles based on their ideas relating to the basic characteristics of the atom. Participants were secondary students of grades 8 , 10, and 12 from Northern Greece $(n=421)$, with specific cohort characteristics (e.g., age, grade, and class curriculum) and individual differences (e.g., formal reasoning, field dependence-independence, and divergent thinking). They observed that students' performance in the tasks was positively associated to their performance in the three cognitive factors, whereas formal reasoning contributed the most to this discrimination. Although the distribution of the student cohort characteristics across the student profiles, was not clearly different, they indicated that the curriculum also played a noticeable role in the formation of the profiles. Another study [28] probed two specific task contexts that were designed in accordance with the corresponding teaching contexts for atomic structure-one based on Bohr's model and the other on the quantum mechanical model. This study aimed to potentially differentiate the initial students' representations of the structure of atoms with the same participants in the study above. They found that, although developmental factors like formal reasoning were associated with a better representation of the structure of atoms, the task context appeared to have the dominant role. Even after accounting for the effects of individual differences, positive associations were found between student cohort characteristics and the representations of atomic structure in context-dependent tasks.

\subsection{Research about Understanding the Structure of Atoms in the Turkish Educational Context}

In the Turkish educational context, several studies attempting to determine chemistry students' mental models of atoms have also been provided. Nakiboğlu et al. [7] studied 25 chemistry and 79 mathematics teacher trainees. Participants were asked to draw a picture of how they imagined the structure of atoms as it was currently accepted by scientists. The study determined that some students did not have a clear model in their mind. Most students' mental models did not represent the most modern theory of atoms. The students had models primarily based on Bohr's chronologically developing atomic theories. Most of the drawings were based on analogical or metaphorical models that had been used in their lessons, e.g., the solar system analogy or the electron cloud and shell metaphor. Yildiz conducted a study with 441 lower and 479 upper secondary chemistry students [29]. She also asked students for a drawing of a contemporary model of the atom, with labels. She quickly found that lower and upper secondary students' mental models parallel each other quite closely and are mainly affected by analogies and historical models. Quantum mechanistic models of the atom were almost absent. In later years, working with 163 Turkish middle school students (grades six, seven, and eight), Çökelez found out that the learners generally have difficulties about the number, size, and movement of particles, as well as the space between them [30]. For example, learners thought that the size of the particles increases when changing from the solid to gaseous state. Çökelez and Yalçın studied three elementary schools with 217 students attending the 7th grade before and after instructions ( $n=215$ after instruction) [31]. They revealed that although the students improved their understanding of the atom after the instructions, they did not sufficiently comprehend and visualize the structure of the atom. Before instructions, more than half of the students thought of atoms as solid spheres and half of the students constructed something like the Bohr atomic model, as explained in the textbook. At the end of the instruction, however, only $5 \%$ of the students managed to present aspects of the modern atomic theory, as intended by the instruction. It was observed that, both, at the beginning and at the end of the instruction, students compared the size of atom with small visible things like lentils, ants, etc. In his study with 126 students, including 76 6th grade and 50 7th grade students, Çökelez intended to determine students' knowledge of the structure and physical properties of the atom [32]. He found that students had difficulty developing a mental image of the atom and they showed a preference for working with complex and abstract models. Karagöz 
and Aslan (2012) developed an open-ended test to determine 45 7th grade students' mental models of the structure of atoms [33]. They found that all the students had an accurate understanding that atoms consisted of protons, neutrons, and electrons, but students had widely different mental models for their actual movements and locations. The study also revealed that students mainly associated atomic structure with analogies, e.g., the solar system. Finally, Kiray recently published a study based on drawings and interviews about prospective science teachers' mental models of atoms [6]. The study also identified students' mental models as having formed around corresponding models taken from the history of chemistry. Unfortunately, the representations of historical models of atomic structure in textbooks and by teachers, are not always scientifically sound, nor are they suitably framed in their historical contexts [5].

In summary, the theoretical framework of this paper combined theories on the formation of mental models with knowledge about common misunderstandings and mistakes made by students, when thinking about sub-microscopic entities, like atoms. This framework is suggested to guide the interpretation of the elements that were identified in the students' drawings of atomic structure and which were preferred by them among the teaching materials. The idea of mental models suggests that each individual learner combines the impressions and knowledge obtained, to their own mental representations. Knowledge about students' potential understanding and their exposure to visual impressions can help better understand why certain elements appear in their imagination and could hopefully guide teaching, to better approach the wrongly combined or neglected aspects.

The originality of the current study lies in its focus on prospective science teachers (PSTs), whereas most previous research mainly addressed students from the middle and high school levels. The approach of this paper was to analyze the single elements of atomic structure preferred by PSTs, and any combinations thereof. This was carried out with the assumption that the models that are regularly selected and presented by teachers and textbooks, do not correctly represent historical models, often yielding incorrect, hybrid models or visualizations [23] in which some aspects are improperly presented, explained, or even neglected [5,20]. In a recent Turkish study, Kiray [6] analyzed drawings of the atom by its comparison to those models used in teaching. The present study started with a thorough analysis, by identifying every single element available in the drawings of the structure of atoms. This inductive analysis was then connected to data from open-ended questions on some features of the atom (e.g., size, visibility, texture of atom), as well as which teaching models most accurately captured a holistic view of PSTs' mental models. The research question was-what elements form the mental models of atomic structure and the features of atoms (e.g., size, visibility, texture of atom) among PSTs, in Turkey, and how are these related to the prevalent representations of teaching models for atomic structure?

\section{Sample and Method}

\subsection{Background and Sample}

Secondary students in Turkey first learn about atomic structure in the 7th and 8th grades. The first unit on atoms deals with the particulate nature of matter. Among other topics, the nucleus-shell structure of the atom and the existence of protons, neutrons, electrons, ions (cations and anions), and molecules are covered. In the 8th grade, students learn about the periodic table of elements and the distribution of electrons in the shells of atoms. As a part of the Turkish high school chemistry curriculum, historic models of the atom are taught from the 9th grade, including Dalton's theory of the existence of atoms, Thomson's model, Rutherford's nucleus-shell model of the atom, and Bohr's atomic theory. This leads into a general introduction of the quantum mechanical theory. This is the first time that students encounter atoms in connection with the orbital concept. Although they are made familiar with quantum numbers and orbital types (s, p, d, f), they are only required to discuss the shapes of sand p-orbitals [34]. Furthermore, these topics and theories are also an important component of the General Chemistry I course at universities in Turkey [35]. 
In their future careers, PSTs will be required to teach about atoms and their structure at elementary levels (7th and 8th grades) before moving on to different historic models of the atom. A total of 141 freshman PSTs from the state university in Konya, Turkey, participated in the study, within two sub-cohorts (sample sizes-73 and 68). The study focused on determining the elements in PSTs' mental models of atomic structure and their preferences for prevalent visual representations of teaching models of atomic structure. All participants in the present study had earned admittance to the university through an entrance exam, which entitled them to a four-year undergraduate science teacher education program. In sub-cohort 1 , we focused on 73 Turkish freshman PSTs' drawings of mental models of atoms (although only 67 of them filled the corresponding task in the questionnaire). The present study was supplemented by data obtained from the second sub-cohort consisting of 68 randomly chosen PSTs (19 freshmen, 16 second year, 16 third year, and 17 senior students). This sub-cohort was asked to answer questions of which atomic model they preferred from the typical textbook images. This was part of a paper and pencil questionnaire. All participants in both sub-cohorts received the content on atomic structure described in the school curriculum. All participants had been taught the historical models of atomic structure at different school levels, and later were taught aspects of the quantum mechanical theory of the atom. All participants were informed about the intentions, nature, and methods of the study. All agreed to participate voluntarily.

\subsection{Data Collection}

The PSTs were given a sheet of paper with the instructions: "How do you visualize a contemporary model of the atom in your mind? Please draw it and name each detail." The PSTs were given as much time to complete their drawings as needed. In the second sample of PSTs, participants were asked to fill out a questionnaire. It included visual representations of a gold bullion, a golden bracelet, copper pieces, and a copper plate. The accompanying question was: "What do you think these materials are made of? Please write your thoughts in detail." Further questions included: "Do you think that all materials are formed of atoms? Can atoms be seen by the naked eye? Do you think scientists had seen atoms? What do you think atoms are made of? How are atoms structured? What do you think about the size of an atom? What do you think about its texture?" For the last question the participants were given six visualizations of atomic models taken from Turkish textbooks (Figure 1). PSTs were asked to choose the diagram that best represented their imagined model of an atom. They were also asked for the second best diagram (if they chose one). They were also required to pick the picture that they disliked the most. They were informed that they could chose more than one option for each category. On average, it took approximately $45 \mathrm{~min}$ to fill in the whole questionnaire.

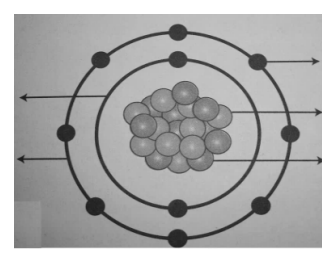

(a)

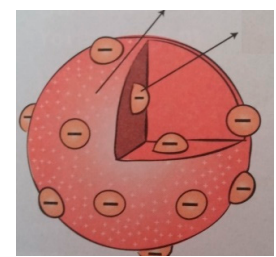

(d)

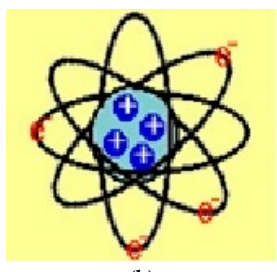

(b)

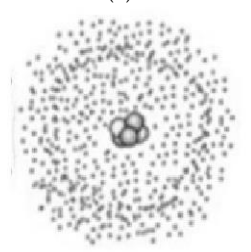

(e)

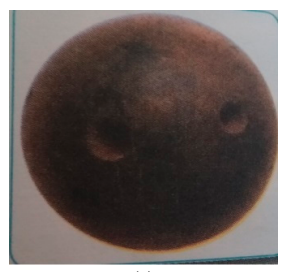

(c)

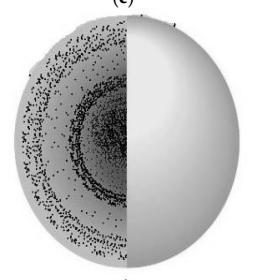

(f)

Figure 1. Various visual representations of atomic structure from Turkish chemistry textbooks [36-38]. (a) Model with 3D-nucleus amd electrons on 2D-circles; (b) Model with nucleus and electroms on orbits in a 3D-plot; (c) Dalton model; (d) Thomson model; (e) Model with nucleus and electrons or charges distributed in the shell; (f) Modell with different shells 


\subsection{Data Analysis}

Analysis of the drawings was performed using a combination of inductive coding, which identified as many graphical and textual elements in the students' drawings as possible, as can also be seen in Papageorgiou et al. [28] and Zarkadis et al. [39]. After saturation in the inductive analysis of the code grid-determined after about half of the data-two researchers independently coded the whole data sample. A code grid was developed for the data to determine relevant categories (see Table 1 below for the categories and codes). Two researchers then carried out independent coding on the whole data sample. The agreement rate of the coding was above $95 \%$, which is considered to be a good agreement rate [40]. The few cases of disagreement were later solved by joint negotiation and recoding. Subsequently, a deductive analysis of the elements in the drawings was performed on the basis of the first round of data analysis, using the theoretical works on mental models $[3,7,11,13,22,29,41]$. Combinations of codes were analyzed to find whether the PSTs' mental models represented certain historical or theoretical models of the atom as visually represented in Turkish chemistry textbooks (Figure 1). The participants' preferences for visual representations from textbooks were then analyzed, using descriptive statistics. The open-ended questions in the second sub-sample were subjected to inductive content analysis by taking previous studies into account [3,22]. Different categories were formed and frequencies were counted for answers from all participants. The study was performed in the Turkish language, and selected answers were later translated for analysis and illustration into English.

Table 1. Categories, codes, and findings from the drawings $(n=67)$.

\begin{tabular}{cc}
\hline Representation & Number of Students \\
\hline General structure & \\
2D structure & 44 \\
Explicit 3D structure & 23 \\
Nucleus-shell structure of the atom & 55 \\
Protons and neutrons & 10 \\
Protons as particles in the nucleus & 27 \\
Label or placeholder for protons & 9 \\
Neutrons as particles in the nucleus & 23 \\
Label or placeholder for neutrons & \\
Shell and electrons & 59 \\
Presence of a shell in the atom & 7 \\
Shell only as outer boundary & 23 \\
Different shells as circles & 29 \\
Different shells as orbits & 29 \\
Explicit drawing of electrons as particles & 14 \\
Label or placeholder for electrons & \\
Charges & 40 \\
Inclusion of negative charges & 26 \\
Inclusion of positive charges & 33 \\
Negative charges connected to electrons & 26 \\
Positive charges connected to electrons &
\end{tabular}

\section{Results}

Visual representations of the structure of atoms varied widely among prospective science teachers in Turkey. Of the 73 students, six participants decided not to provide any drawing at all. Although only asked to represent one contemporary model of atoms, two of the students wanted to demonstrate that they are aware of the different historical models of the atom and provided different visualizations. One student tried to visualize the Dalton, Thomson, and Bohr atomic models. The other one included two more models and named them—-the Rutherford model and a 'modern atomic model'. Both students, 
however, decided to present only two-dimensional structures without providing explicit indications for the space-filling character of the atom.

Among the students who provided drawings, about two-thirds opted for a two-dimensional representation of the atom (44 out of 67). Table 1 provides an overview of these representations, and Figure 2 provides some examples. The other 23 participants explicitly added graphic information indicating that the atom was a three-dimensional entity. A total of 55 out of 67 students opted for drawing a nucleus-shell structure of the atom. Ten people drew protons in the nucleus, with another 27 either drawing with labels or just using a symbolic place holder ( $\mathrm{p}$ or $\mathrm{p}+$ ). Nine and twenty-three drawings, respectively from the two sub-cohorts, showed neutrons. One student drew and labeled electrons in the nucleus.

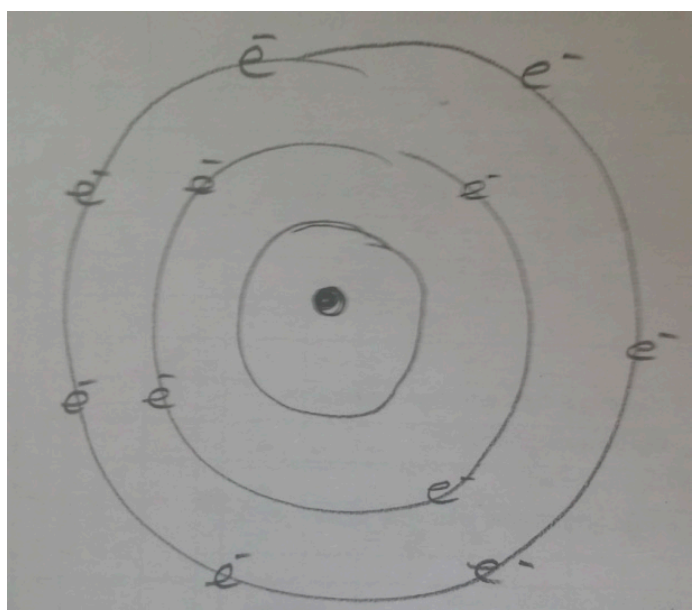

(a)

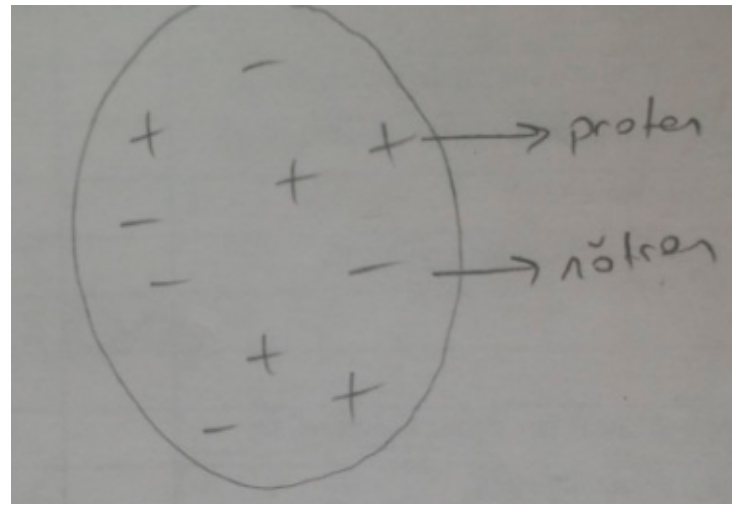

(c)

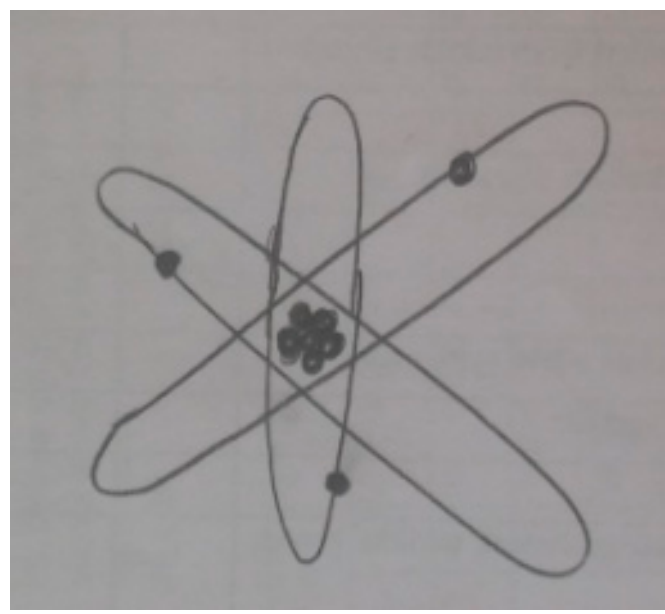

(b)

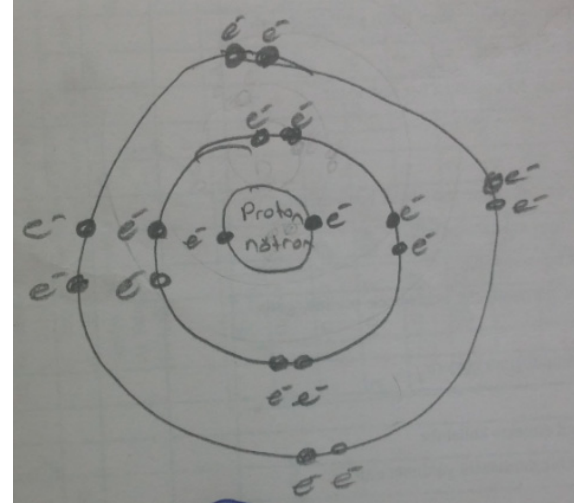

(d)

Figure 2. Examples of student drawings. (a) 2D-structure with electrons as symbols on circles and no structure of the nucleus; (b) 3D-structure with electrons on orbits and a nucleus made up by particles; (c) No nucleus-shell structure with protons and electrons as charges (no neutrons); (d) Structure with nucleus and shell, protons and neutrons not as particles and electrons in pairs on circles.

A total of 59 out of the 67 students who provided a drawing, drew something resembling an atomic shell. Seven people used the shell only to designate the outer boundary of the atom. Of the other 52 students, 23 drew different shells within the atom, while 29 drew circles or orbits where the electrons are located or move, within the shell. With regard to the circles or orbits, 32 students preferred to provide two-dimensional drawings only (similar to Figure 1a), whereas 20 provided a three-dimensional structure mainly linked to the idea of orbits (similar to Figure 1b). Using corresponding labeling, the last four students tried to visualize the main structure of the atom by electron clouds (2), orbitals (1), or one orbital for all electrons (1). 
A total of 53 out of the 67 students explicitly referred to electrons in their drawings. Many only mentioned electrons at the symbolic level (e or e-), but 29 drew them explicitly as particles. Four students provided images of electrons spread in the atom (similar to Figure 1d,e). Twenty-eight participants drew them on circles in a two-dimensional structure (similar to Figure 1a) and eighteen used three-dimensional orbits (similar to Figure 1b). All students who showed circles or orbits visualized the electrons as being on the circle or the orbit. None of the students who used the shell concept, drew electrons within the shells or indicated that the shells are formed by the electrons. Corresponding illustrations for such information are, however, also not common in Turkish chemistry textbooks.

With potentially considering that some aspects of the drawings are just as likely a result of the challenges in drawing an atom, 16 of the 67 students decided not to explicitly include particle charges in their drawings. A total of 40 people included negative charges, but only 26 showed positive charges. Thirty-three drawings explicitly connected the negative charges with the electrons, but only 20 did the same with the positive charges for the protons. It seems that electrons with their negative charges were more familiar or important to the PSTs than protons with their positive ones, or it could be that drawing several protons in a tightly clustered nucleus was considered problematic. This might make sense in terms of chemical reactions as a re-arrangement of electrons through electron transfer or by forming chemical bonds. However, this would be an incomplete picture, since the isolated atom would need to be thought of as an electrically neutral entity before electron loss or gain occurs. Seven of the students spread the negative charges throughout the atom (one of them named this a "cloud" surrounding the nucleus) and six others also spread out the positive charges.

The distribution of responses from the second sample of students, for the six diagrams represented in Figure 1 is given in Table 2. Although the student teachers were given the opportunity to choose more than one model for each category presented in Figure 1, forty-two student teachers chose only one model for the "most-liked" category. Twenty-two student teachers chose two models, and a total of four selected three models. For the "liked" category, one student teacher chose all six models. Thirty-nine participants chose only one model. Only 25 participants selected two models and three people chose three models. For the "not liked" category, 28 student teachers chose only one model. Another 22 people selected two models. Only 17 participants chose three models for this category.

Overall, the students in this sub-sample preferred models that fell in line with what the first sub-sample group of this study drew in their pictures (Figure 1a,b); namely, two- or three-dimensional structures including electrons on circles or orbits around the nucleus. Both representations are models based on earlier and later interpretations of Bohr's atomic theory. Both models are not in line with the quantum mechanical theories of the atom. Figure 1a is, however, well-suited to working concretely with issues such as redox reactions or simple interpretations of chemical bonding, especially when it comes to teaching and learning at the junior high school level. Nevertheless, the figure neglects any three-dimensional structure in atoms. Figure $1 \mathrm{~b}$ is perhaps the most understandable because of the analogy to the solar system, although most planets in our solar system rotate around the sun in the same plane. The figure presents the three-dimensional nature of the atom. It is, however, neither in accordance with the quantum mechanical theory, nor functional in terms of predicting or explaining issues like redox reactions and chemical bonding.

The most disliked visual representation was Figure 1c, which is an atom without any visible internal structure. This model might be referred to as Dalton's model of the atoms, a theory that did not propose any inner structure for the atom due to lack of data at the time. It seems clear to most of the student teachers from this sub-sample, that atoms do have an inner structure, since almost all participants in the first sub-sample drew an inner structure of the atom. Figure 1e was also highly disliked. It has close relations to Thomson's short-lived "plum pudding" theory of atomic structure. This dislike also correlated with the drawings from the first sub-sample, since only six teachers drew electrons or protons (or the corresponding charges) that more-or-less statistically spread around in the body of the atom. Most students seemed to be aware that both of these models are considered outdated today and do not represent our current knowledge of atomic structure. 
Table 2. Frequency of students preferences for models presented in Figure $1(n=68)$ *.

\begin{tabular}{|c|c|c|c|c|c|c|c|c|c|c|c|c|c|c|c|}
\hline & \multicolumn{5}{|c|}{ Most Liked (N) } & \multicolumn{5}{|c|}{ Liked (N) } & \multicolumn{5}{|c|}{ Not Liked (N) } \\
\hline & Freshmen & Sophomore & Junior & Senior & Total & Freshmen & Sophomore & Junior & Senior & Total & Freshmen & Sophomore & Junior & Senior & Total \\
\hline 1.a & 9 & 4 & 9 & 6 & 28 & 6 & 8 & 6 & 6 & 26 & 2 & 1 & 1 & 1 & 5 \\
\hline 1.b & 8 & 14 & 10 & 7 & 39 & 5 & 2 & 6 & 5 & 18 & 3 & - & 1 & 2 & 6 \\
\hline 1.c & 1 & - & 1 & - & 2 & 2 & 1 & 1 & 3 & 7 & 14 & 14 & 12 & 12 & 52 \\
\hline 1.d & 1 & 1 & 1 & 2 & & 4 & 7 & 5 & 3 & 19 & 7 & 1 & 6 & 6 & 20 \\
\hline 1.e & 5 & 2 & 3 & 5 & 15 & 6 & 1 & 8 & 2 & 17 & 6 & 5 & 3 & 5 & 19 \\
\hline 1.f & 2 & 2 & 2 & 1 & 7 & 8 & 3 & 4 & 5 & 20 & 4 & 3 & 7 & 5 & 19 \\
\hline
\end{tabular}

* Since students could choose more than one option, total values are more than the number of participants. 
The final two representations (Figure 1e,f) try to illustrate the quantum mechanical character of atomic structure. Figure $1 \mathrm{f}$ does so by explicitly visualizing the three-dimensional structure of atoms, whereas in Figure 1e this aspect remains unclear. Both figures were disliked more than the models based on Bohr's theory, but less than the very simple models of atomic structure (Figure 1c). These models seem to gain popularity with students maturing over time. This might explain why they played such a minor role in the drawings made by the first sub-sample of this study.

In both sub-samples, the preferred models are imaginable, concrete, and functional [3]. Students tend to draw models of atoms which show concrete particles with discrete parts [42]. It seems that these characteristics were more important to the students than modeling all contemporary findings about reality in the best way possible. For a physicist, quantum mechanical models offer the most comprehensive and functional means to explain the quantum mechanical phenomena. For chemists, models like Figure 1a might be considered the most functional because they allow easier predictions and explanations than Figure 1e,f. This is true for attempts to describe the formation of ions or covalent bonds during chemical reactions, which are consistent with these concrete figures.

In the open-ended questions, all participants stated that all matter is made up of atoms, as seen in Table 3. A total of 57 people agreed that atoms are too small to be seen by the naked eye. Forty-four respondents thought that although atoms cannot be seen by naked eye, they can be viewed using specific technological and electronic devices. A further 19 students stated that atoms can never be seen under any circumstances. Five replies revealed that the teachers were not sure whether scientists had ever seen atoms or not. Some of the remaining students tried to explain aspects of the size of atoms using various explanations, several of which were scientifically unsound. For example, one student explained: "The size of atom is different for each material. For instance, the atoms of a material with $1 \mathrm{~m}$ diameter are not in the same size as the atoms of a material with $1 \mathrm{~nm}$ diameter".

Table 3. Frequency of prospective science teacher responses in six conceptual categories concerning atomic structure $(n=68)$.

\begin{tabular}{|c|c|c|c|}
\hline Categories & Codes/Attributes & Frequency $(f)$ & Percentage $(\%)$ \\
\hline 1.Elements & $\begin{array}{l}\text { Student used the term elements for the visual given } \\
\text { in the first question of paper-pencil test. }\end{array}$ & 22 & 32 \\
\hline \multirow[t]{2}{*}{ 2.Atoms } & $\begin{array}{l}\text { Student used the term atoms for the visual given in } \\
\text { the first question of paper-pencil test. }\end{array}$ & 42 & 62 \\
\hline & No response & 4 & 6 \\
\hline 3.Composition of Matter & All substances made up of atoms & 68 & 100 \\
\hline \multirow{3}{*}{ 4.Size of Atoms } & Atom is too small to be seen & 57 & 84 \\
\hline & Other & 7 & 10 \\
\hline & No response/Don't know & 4 & 6 \\
\hline \multirow[t]{3}{*}{ 5.Visibility of Atoms } & $\begin{array}{c}\text { Atom cannot be seen by naked eye; however it can } \\
\text { only be seen by electronic or technological devices } \\
\text { like microscope. }\end{array}$ & 44 & 65 \\
\hline & Can't be seen & 19 & 28 \\
\hline & Not sure & 5 & 7 \\
\hline \multirow{5}{*}{ 6.Texture of Atoms } & Atom is solid. & 19 & 28 \\
\hline & $\begin{array}{l}\text { The texture of atom changes according to the type } \\
\text { of the material. }\end{array}$ & 22 & 32 \\
\hline & $\begin{array}{c}\text { The texture of atom changes according to the state } \\
\text { of matter. }\end{array}$ & 5 & 7 \\
\hline & No response/Don't know & 12 & 18 \\
\hline & Other & 10 & 15 \\
\hline
\end{tabular}

Seven of the students tried to explain the size of atoms with explanations and analogies from daily life. For instance, one person explained atomic size like this: 
"The size of the atom is directly proportionate to its diameter. Electrons are located in orbits. If an atom has more electrons, it has more orbits. That's why it is big. For example, an atom of hydrogen has an electron and an orbit. On the other hand, the atom of sodium has 11 electrons and three orbits."

It seems that in this case, the image of orbits (like Figure 1b) is mixed up with the visualization of shells (like in Figure 1a or f). Another student explained the size of atoms with a comparison: "The size of an atom is as big as a football ball if you compare it to the world".

The student teachers' explanations about the size and visibility of atoms also provided some information about their understanding of the character and emergence of scientific models, e.g., in the case of atomic structure. According to the levels by presented Grosslight et al. [24] some participants held a somewhat naïve view of how models of the atom emerged. Examples include:

"Atoms can be seen by the help of a microscope. They cannot be seen by the naked eye. Since the existence of atoms is based on a scientific foundation, scientists must have seen it."

"I think atoms can be seen because scientists propounded many atomic models. They could not have done this without seeing."

"There are a lot of studies, models and laws related to atoms. Therefore, scientists must have seen atoms."

Harrison and Treagust also pointed out that students might think that the visualizations of the atom they see in textbooks, on TV, etc., are real, because they think that scientists have seen atoms [3]. Other answers were better elaborated:

"An atom cannot be seen with your eye. It cannot be seen by microscope, either. Its existence can only be accepted. For this reason, scientists form models."

"Atoms cannot be seen by your eye. Different scientists have come up with different theories and proposed various models. The correctness of these theories has been either proved or refuted, and then new models have been developed."

"To me, atoms can never be seen under any circumstances. I don't think there is a scientist who has seen atoms. If anyone had seen one, Bohr, for example, wouldn't have developed an atomic model in the way he did."

The students had also various ideas about the question related to the texture and properties of atoms. A total of 19 (out of 68) stated that atoms are solid, but 22 stated that solidity and softness differ from one material to another. Five people stated that the texture of atoms changes according to the state of matter. Twelve participants responded that they do not know the answer. Ten respondents gave answers such as atoms have a flexible structure, atoms do not have any texture, or atomic texture cannot be commented upon. One student described the texture of atoms changing according to the type of matter:

"The texture of an atom is solid if the matter is solid; it has a soft structure if the matter is soft. For example, the atom of sodium has a soft structure. The atom of gold is more solid when compared to the atom of sodium."

Studies by Ben-Zvi et al. [43], Anderson [44], and Lee et al. [45] have also found that some students believe that the characteristics of atoms and molecules are similar to the substance's macroscopic properties. For instance, Anderson discovered that some students thought that submicroscopic particles had colors. These findings showed that students sometimes attribute the observable macroscopic properties of matter to the atoms themselves. This might lead learners to think that each particle of a 
specific type of matter had properties identical to the recognizable, macroscopic physical features (e.g., color) [46].

A final observation was the tendency of some students to draw parallels between (or even mix) concepts of atomic structure and living organisms. The following two excerpts recall the notion of "Living Atoms" from Harrison and Treagust's study [3].

"All matter is comprised of smallest building blocks. This is an 'atom' in non-living things, a 'cell' in living things... ". "Cells, the smallest building blocks of living things, are comprised of numerous atoms formed of protein, carbohydrates and fat."

Harrison and Treagust explained that biology and chemistry often use similar terms such as nucleus and shells [3]. This causes confusion in some learners who cannot differentiate between them.

\section{Discussion}

The findings of this study document a large variety of visual and symbolic elements of the structure of atoms in the drawings of student teachers. The results also showed that many elements that students should know are neglected by many of them when asked to provide a drawing of a contemporary visual representation of atomic structure. Clearly, the models and visual representations of atomic structure used in teaching had the greatest influence on the graphical elements of their illustrations. Two students provided more than one model to explicitly show their awareness of the differences between models and visual representations. There were central elements of the two models that were preferred by the PSTs, in both parts of this study; namely, a two-dimensional and three-dimensional visualizations based on atomic theory related to the works of Bohr. Concrete and functional models were preferred by most students, while only a few students tried to provide representations of atomic theory based on the quantum mechanical theory. Vosniadou [11] stated that "various mental models ... can be explained as attempts on the part of the children to reconcile aspects of the model to which they are exposed through instruction with their initial model" (pp. 62-63). Unfortunately, students' prior knowledge and experience is often linked to an incomplete understanding in class. This leads to various alternative mental models which are produced during the process of learning [11,47]. From this study, it appeared that the models used in school instructions were the basic source of images selected by the PSTs, when sketching a model of atomic structure. However, when pressed to imagine what an atom looks like or what properties it has, the learner's everyday life experiences started to play an important role.

Similar to previous studies [6,7], the current study also found that the models presented in textbooks and used by educators were the ones that had the most influence on the PSTs' mental models of the structure of atoms. Nakiboğlu et al. determined that most prospective teachers preferred to visualize atoms similarly to Bohr's theories of atomic structure [6]. Most of their mental models showed clear parallels with the corresponding visualizations they have seen in class. The present study indicated that this still holds true for Turkish students (see also [6]), even after 15 years of the initial study by Nakiboğlu [7]. This interpretation was supported by the selection activity carried out by the second sub-sample in the current study. Many students still preferred to draw or select their image of an atomic model from commonly used analogies and metaphors, like the solar system analogy or the shell metaphor [7,22,33]. Similar to the findings by Harrison and Treagust [3], our results illustrated that there were two major groups of PSTs—one referred to electron shells represented by circles carrying the electrons and the other referred to electrons moving in fixed orbits around the nucleus. No one from the first sample used shells explicitly in a three-dimensional manner, or as a space containing electrons, or as a construct formed by their presence.

We could derive further information from the second sub-sample in this study, especially concerning the size and properties of atoms. Most PSTs agreed that no one can see atoms, in detail, with the naked eye. Of those who suggested that we can see them with technological devices, it remained unclear whether they had heard about corresponding modern technologies like scanning 
tunneling microscopy or simply believed in the power of science and technology. The reality is that even with such advanced technologies, we still cannot see atoms with our eyes, but we can make images of them with the proper devices. These devices have already been suggested as topics for discussion in early school science teaching [48]. A much more critical factor was that many students believed that models of atoms can only be made if scientists have really seen atoms before. This mistake, as well as the transfer of macroscopic properties to atoms and corresponding models about them, demand a better and more thorough education on the nature and purpose of modeling in science [24,49] This includes an explicit discussion of what models can and cannot do, in addition to what they really are and are capable of doing for science.

Students need guidance to help them comprehend the valid and invalid features of each particular model and models in general. Harrison and Treagust [22] found parallels in the different levels of understanding models and modeling in science education (see Grosslight et al., [24]) with dualism, multiplism, and relativism [50]. According to the model levels suggested by Grosslight et al. [24], students' epistemological status is a key factor if model-based instruction is to be successful. For instance, a student at a naïve level of understanding might think that because scientists have seen atoms, the model must be an exact copy of the real atom. This student will be probably a dualist and not accept multiple models, whereas a relativist student will accept multiple models. Dynamic progress could be sustained by combining challenging instruction with regular assessment [51] and by using formative assessment by focusing on monitoring and stimulating students' modeling skills [52].

\section{Conclusions}

In light of the current study, we suggest that science teacher educators explicitly discuss the role of analogies and metaphors in both common language and science, before using them with students in science classes. This is particularly important for the solar system and cell analogies, and the shell metaphor that are often found in science lessons. Modeling sub-microscopic structures is also a topic which should fall under this explicit discussion. As suggested by Harrison and Treagust, teachers should make strong connections between the attributes from the analogy or metaphor to the atom, but they also need to openly discuss the differences and limitations of such examples [3,22]. Gilbert and Watts [53] and Harrison and Treagust [3] accentuated the fact that one source of alternative conceptions stems from the linguistic differences between scientific terms and everyday words. Textbooks, educators, and students often attribute different meanings to terms that are commonly used in both science and everyday language.

It should be clear that in contemporary models of atoms the electrons neither "fly around" in the atoms, nor are they concretely "located" in or on any kind of shell or circle. However, this is exactly what might be interpreted by PSTs as "forming shells", if teacher educators choose the shell metaphor to explain quantum numbers and their corresponding energy levels. The situation can become even worse if the teacher educator turns to an onion and its layers of shells, in an act of desperation to finally "help" the overwhelmed learners understand this very complicated issue. This is not an argument against teaching and learning a modern interpretation of Bohr's atomic model, in which electrons from the atomic shell correspond with certain levels of energy, and in which the nucleus is formed by protons and neutrons. The Bohr model is concrete and functional and fits for many purposes in explaining basic chemical phenomena. Not every contemporary model of atomic structure needs to be based in a thorough understanding of quantum mechanical theory. However, the relationship between sub-atomic particles and the limitations of older interpretations of Bohr's atomic theory, like being expressed by the solar system analogy, should be made clear.

Science teacher educators should seek to prevent the generation of alternative or undesired misconceptions among their students. It is vitally important to consider the effects of the poorly-conceived usage of pictures and language as examples in science teaching. If science teacher educators feel the need to use an analogy, metaphor, or visualization in class, they need to familiarize their students with the inherent elements in the approach. They must identify both the shared and 
unshared attributions that their learners will make [3,54-56]. Likewise, science educators must include specific instruction time in which students can improve their modeling skills. As for the case of modelling climate change [49,57], educators can conduct their own modelling activities or analyze how models are made and used. This would aid PSTs in understanding the role and purpose of models in science. It would also reveal the corresponding analogies, metaphors, and visualizations that are given as a guide for interpreting and communicating non-observable aspects of matter, like atomic structure. This is specifically true if a groups of PSTs obviously confuses a model with reality, or with other models in which they have encountered [3,55,58].

The findings of Nakiboğlu et al. from 15 years ago still are relevant today [7]. Most PSTs in our study described mental models that did not include the quantum mechanical nature inherent in the most current models of the atom. Most of the participants seemed comfortable to stay with ideas of the atom, based in Bohr's works. Yet, the question remains whether they are simply unaware of the quantum mechanical character of atoms, or whether they willingly preferred to select the most discrete and useful models (from chemistry's perspective), instead of describing the most recent, modern interpretations of atomic structure. Teaching, as a profession, needs to explicitly state its intentions when teaching models of atomic structure [5]. If the model is meant for explanations and predictions of chemical behavior, then Bohr's atomic theory and the corresponding models (Figure 1a) remain very useful. More recent interpretations of atomic structure are more suitable if the prospective science teacher is trying to understand the quantum mechanical nature of atoms. Visualizations like Figure $1 \mathrm{~b}$ are neither practical nor instructive for such purposes. Nakiboğlu et al. wrote in 2002 that Turkish teachers generally start off the topic of atomic structure with a "solar system" analogy [7]. Perhaps this is still the case today-or we could call attention to the issue of Turkish science teachers' views and instructions on atomic structure, for future research. If we acknowledge that models like Figure $1 \mathrm{~b}$ are neither good for understanding the quantum mechanical nature of atoms nor for making any predictions of chemical reactions, we need to react. We must raise the question whether it would be better to completely ignore the solar system analogy, replace it with something better, or clearly state both the limitations of this analogy and its inaccurate response from our learners.

Although the modern atomic theory is more detailed now than what it was in the past, introductory science and chemistry textbooks in Turkey still prefer to show images related to Bohr's older theories of the atom, as documented by Nakiboğlu et al. [7]. Thus, students internalize outdated and simplistic models related to Bohr (electrons on fixed orbits or shells), as such images look like our solar system, an onion, or a shooting target. As science education advances, different historical theories of atomic structure are taught one after another in Turkey. This often occurs in an unrelated and disjointed fashion, as is the case in other countries around the world [5,59]. Sometimes this happens without even contrasting the older models with the current, more advanced theories of atomic structure. There also seems to be a lacking, when it comes to emphasizing the functions and limitations of the different models presented in secondary school chemistry courses. This needs to be rectified. Detailed reflection and a carefully thought-out curriculum are needed to make learners familiar with the nature of scientific models. They also need to learn that there are competing models and that different types of models have different purposes [60].

We have seen that, although modern students should know that there are more advanced atomic models which reach beyond orbits and shells, most of the PSTs in the present study stubbornly clung to models based on older interpretations of Bohr's theories of the atom. It is possible that the PSTs merely forgot about the quantum mechanical models of the atom. It is equally likely that they preferred and chose models which are discrete or functional when asked questions in the context of chemistry. We would suggest a better-reflected instruction about the different models in the modern classroom for science teacher educators. This should include making it clear to PSTs what the historical framework of each model is, what specific purpose the model was created for, and what the benefits and limitations of each of the models are. Alternatively, one could also follow an approach which avoids the use of different historical atomic models in order to approach a coherent structure of what the contemporary 
knowledge of atomic structure comprises. This latter approach has already been successfully tested in German junior high school chemistry education [5]. It proved especially effective if connected to innovative forms of pedagogy [61]. Either way, especially for science teacher education, we suggest a larger emphasis on the three-dimensional structure of atoms, an avoidance of the idea that electrons merely move around the nucleus in fixed orbits, and an explicit discussion of the fact that the electrons in the shell metaphor actually create the shells rather than being placed in them. Thus, the PSTs might integrate this point of view to their courses in the future.

We might suggest that the time might even be right to conduct a meta-study on the existing literature, since students' understanding of atomic structure is so fundamental to building a robust understanding of chemistry. More work is certainly needed in this area for students across the world and at multiple levels of their education, and there is an increasing amount of study on how students understand the structure of atoms.

\section{Limitations}

This study is limited, since it only referred to the Turkish educational context. Additionally, the method of analyzing students' visual representations through drawings might also pose a limitation. By using students' visual expressions, we attempted to gain insights into students' mental models, but such mental models are unique to individuals and the drawings might not express all aspects of a given belief or conception (e.g., whether a drawing on paper intends to provide a representation of a two- or three-dimensional structure, needs to be interpreted). As Coll and Treagust have already stated, the findings of such studies are inherently limited to the participants' expressed mental models [13]. Nevertheless, the respondents are complex individuals and might have ignored other possible factors such as their own subconscious beliefs. They might also have presented other possible factors as answers, in an attempt to find cues as to what the interviewer really wants, thereby skewing the data. However, this is all part of the human condition and was vindicated by the close relationship of the data secured from the first and second sub-cohorts. While data from two different sub-cohorts were combined, interpretations linking the two sub-cohorts must be analyzed carefully, to reach a better understanding on this topic.

Author Contributions: Conceptualization, A.D. and I.E.; methodology, A.D. and I.E.; validation, A.D. and I.E.; formal analysis, A.D. and I.E.; investigation, A.D., N.K. and I.E.; data collection, A.D. and N.K.; data curation, A.D. and I.E.; writing—original draft preparation, A.D. and I.E.; review and editing, A.D., N.K. and I.E.

Funding: This research received no external funding.

Conflicts of Interest: The authors declare no conflict of interest.

\section{References}

1. Duit, R. On the role of analogies and metaphors in learning science. Sci. Educ. 1991, 75, 649-672. [CrossRef]

2. Duit, R.; Treagust, D.F. Students' conceptions and constructivist teaching approaches. In Improving Science Education; Fraser, B.J., Walberg, H.J., Eds.; The National Society for the Study of Education: Chicago, IL, USA, 1995.

3. Harrison, A.G.; Treagust, D.F. Secondary students mental models of atoms and molecules: Implications for teaching science. Sci. Educ. 1996, 80, 509-534. [CrossRef]

4. Taber, K.S. An alternative conceptual framework from chemistry education. Int. J. Sci. Educ. 1998, 20, 597-608. [CrossRef]

5. Eilks, I. Teachers' ways through the particulate nature of matter in lower secondary chemistry teaching: A continued change of different models vs. a coherent conceptual structure? In Concepts of Matter in Science Education; Tsaparlis, G., Sevian, H., Eds.; Springer: Dordrecht, The Netherlands, 2013; pp. 213-230.

6. Kiray, S.A. The pre-service science teachers' mental models for concept of atoms and learning difficulties. Int. J. Educ. Math. Sci. Technol. 2016, 4, 147-162. [CrossRef] 
7. Nakiboğlu, C.; Karakoç, Ö.; Benlikaya, R. Öğretmen adaylarının atomun yapısı ile ilgili zihinsel modelleri [Prospective Teachers' Mental Models of Atomic Sructure]. Abant İzzet Baysal Üniversitesi Eğitim Fakültesi Dergisi 2002, 2, 88-98.

8. Gunstone, R.; White, R. Goals, methods and achievements of research in science education. In Improving Science Education; Millar, R., Leach, J., Osborne, J., Eds.; Open University Press: Buckingham, UK, 2000; pp. 293-307.

9. Ayas, A. Kavram Öğrenimi [Concept Learning]. In Kuramdan Uygulamaya Fen ve Teknoloji Öğretimi; Çepni, S., Ed.; Pegem Yayıncıllk: Ankara, Turkey, 2006; pp. 125-151.

10. Vosniadou, S.; Brewer, W.F. Mental models of the earth: A study of conceptual change in childhood. Cogn. Psych. 1992, 24, 535-585. [CrossRef]

11. Vosniadou, S. Capturing and modelling the process of conceptual change. Learn. Instr. 1994, 4, 45-69. [CrossRef]

12. Franco, C.; Colinvaux, D. Grasping mental models. In Developing Models in Science Education; Gilbert, J.K., Boulter, C.J., Eds.; Kluwer: Dordrecht, The Netherlands, 2000; pp. 93-118.

13. Coll, R.K.; Treagust, D.F. Investigation of Secondary School, Undergraduate, and Graduate Learners' Mental Models of Ionic Bonding. J. Res. Sci. Teach. 2003, 40, 464-486. [CrossRef]

14. Norman, D.N. Some observations on mental models. In Mental Models; Gentner, D., Stevens, A.L., Eds.; Lawrence Erlbaum: Hillsdale, MI, USA, 1983; pp. 7-14.

15. Taber, K.S. Constructing and communicating knowledge about chemistry and chemistry education. Chem. Educ. Res. Pract. 2014, 15, 5-9. [CrossRef]

16. Glynn, S.M.; Duit, R. Learning Science in the Schools: Research Reforming Practice; Lawrence Erlbaum: Mahwah, NJ, USA, 1995.

17. Thiele, R.B.; Treagust, D.F. The nature and extent of analogies in secondary science textbooks. Instr. Sci. 1994, 22, 61-74. [CrossRef]

18. Thiele, R.B.; Treagust, D.F. An interpretive examination of high school chemistry teachers' analogical explanations. J. Res. Sci. Teach. 1994, 31, 227-242. [CrossRef]

19. Johnstone, A.H. Why is science difficult to learn? Things are seldom what they seem. J. Comput. Assist. Learn. 1991, 7, 75-83. [CrossRef]

20. Eilks, I.; Möllering, J.; Valanides, N. Seventh-grade students' understanding of chemical reactions—Reflections from an action research interview study. Eurasia J. Math. Sci. Technol. Educ. 2007, 4, 271-286. [CrossRef]

21. Eilks, I. Students' understanding of the particulate nature of matter and some misleading illustrations from textbooks. Chem. Act. 2003, 69, 35-40.

22. Harrison, A.G.; Treagust, D.F. Learning about atoms, molecules, and chemical bonds: A case study of multiple-model use in grade 11 chemistry. Sci. Educ. 2000, 84, 352-381. [CrossRef]

23. Justi, R.; Gilbert, J. History and philosophy of science through models: Some challenges in the case of 'the atom'. Int. J. Sci. Educ. 2000, 22, 993-1009. [CrossRef]

24. Grosslight, L.; Unger, C.; Jay, E.; Smith, C.L. Understanding models and their use in science: Conceptions of middle and high school students and experts. J. Res. Sci. Teach. 1991, 28, 799-822. [CrossRef]

25. Çökelez, A.; Dumon, A. Atom and molecule: Upper secondary school French students' representations in long-term memory. Chem. Educ. Res. Pract. 2005, 6, 119-135. [CrossRef]

26. Park, E.J.; Light, G. Identifying atomic structure as a threshold concept: Student mental models and troublesomeness. Int. J. Sci. Educ. 2009, 31, 233-258. [CrossRef]

27. Papageorgiou, G.; Markos, A.; Zarkadis, N. Understanding the atom and relevant misconceptions: Students' profiles in relation to three cognitive variables. Sci. Educ. Int. 2016, 27, 464-488.

28. Papageorgiou, G.; Markos, A.; Zarkadis, N. Students' representations of the atomic structure-The effect of some individual differences in particular task contexts. Chem. Educ. Res. Pract. 2016, 17, 209-219. [CrossRef]

29. Yıldız, H.T. İlköğretim ve ortaöğretim öğrencilerinin atomun yapısı ile ilgili zihinsel modelleri [Primary and Secondary Students' Mental Models Concerning Atomic Structure]. Master's Thesis, Balıkesir University, Balıkesir, Turkey, 29 August 2006.

30. Çökelez, A. Students' (Grade 7-9) ideas on particle concept: Didactical transposition. Hacet. Univ. J. Educ. 2009, 36, 64-75.

31. Çökelez, A.; Yalçın, S. The analysis of the mental models of students in grade-7 regarding atom concept. Element. Educ. Online 2012, 11, 452-471. 
32. Çökelez, A. Junior high school students' ideas about the shape and size of the atom. Res. Sci. Educ. 2012, 42, 673-686. [CrossRef]

33. Karagöz, Ö.; Sağlam-Arslan, A. İlköğretim öğrencilerinin atomun yapısına ilişkin zihinsel modellerinin analizi [Analysis of mental models of atomic structure of elementary school students]. Türk Fen Ë̆itimi Dergisi 2012, 9, 132-142.

34. Ministry of National Education (MoNE). High School Chemistry Curriculum; MoNE: Ankara, Turkey, 2018.

35. Nakiboğlu, C. Using word associations for assessing non major science students' knowledge structure before and after general chemistry instruction: The case of atomic structure. Chem. Educ. Res. Pract. 2008, 9, 309-322. [CrossRef]

36. Ministry of National Education (MoNE). High School 9th Grade Chemistry Course Book; Başak Printing: Ankara, Turkey, 2011.

37. Ministry of National Education (MoNE). High School 10th Grade Chemistry Course Book; Başak Printing: Ankara, Turkey, 2012.

38. Ministry of National Education (MoNE). High School 9th Grade Chemistry Course Book; Tuna Printing: Ankara, Turkey, 2015.

39. Zarkadis, N.; Papageorgiou, G.; Stamovlasis, D. Studying the consistency between and within the student mental models for the atomic structure. Chem. Educ. Res. Pract. 2017, 18, 893-902. [CrossRef]

40. Miles, M.B.; Huberman, A.M. Qualitative Data Analysis; Sage: Thousand Oaks, CA, USA, 1994.

41. Taber, K.S. Mediating mental models of metals: Acknowledging the priority of the learner's prior learning. Sci. Educ. 2003, 87, 732-758. [CrossRef]

42. Chi, M.T.H.; Slotta, J.D.; de Leeuw, N. From things to process: A theory of conceptual change for learning science concepts. Learn. Instr. 1994, 4, 27-43. [CrossRef]

43. Ben-Zvi, R.; Eylon, B.; Silberstein, J. Is an atom of copper malleable? J. Chem. Educ. 1986, 63, 64-66. [CrossRef]

44. Anderson, B. Pupil's conceptions of matter and its transformation (age 12-16). Stud. Sci. Educ. 1990, 18, 53-85. [CrossRef]

45. Lee, O.; Eichinger, D.C.; Anderson, C.W.; Berkheimer, G.D.; Blakeslee, T.D. Changing middle school students' conceptions of matter and molecules. J. Res. Sci. Teach. 1993, 30, 249-270. [CrossRef]

46. Adadan, E. Model-Tabanlı Öğrenme Ortamının Kimya Öğretmen Adaylarının Maddenin Tanecikli Yapısı Kavramını ve Bilimsel Modellerin Doğasını Anlamaları Üzerine Etkisinin İncelenmesi [Investigating the Effect of Model-Based Learning Environment on Preservice Chemistry Teachers' Understadings of the Particle Theory of Matter and the Nature of Scientific Models]. OMU J. Fac. Educ. 2014, 33, 378-403.

47. Strike, K.A.; Posner, G.J. A revisionist theory of conceptual change. In Philosophy of Science, Cognitive Psychology, and Educational Theory and Practice; Duschl, R.A., Hamilton, R.J., Eds.; State University of New York Press: New York, NY, USA, 1992; pp. 147-173.

48. Eilks, I.; Möllering, J.; Ralle, B. Scanning tunneling microscopy-A teaching model. Sch. Sci. Rev. 2004, 85, 17-19.

49. Taber, K.S. Towards a curricular model of the nature of science. Sci. Educ. 2008, 17, 179-218. [CrossRef]

50. Perry, W.G. Forms of Intellectual and Ethical Development in the College Years; Holt, Rinehart and Winston: New York, NY, USA, 1970.

51. Van der Veer, R.; Valsiner, J. Understanding Vygotsky: A Quest for Synthesis; Blackwell: Oxford, UK, 1991.

52. Black, P.J. Formative and summative assessment by teachers. Stud. Sci. Educ. 1993, 21, 41-97. [CrossRef]

53. Gilbert, J.K.; Watts, D.M. Concepts, misconceptions and alternative conceptions: Changing perspectives in science education. Stud. Sci. Educ. 1983, 10, 61-98. [CrossRef]

54. Glynn, S.M. Explaining science concepts: A teaching-with-analogies model. In The Psychology of Learning Science; Glynn, S., Yeany, R., Britton, B., Eds.; Lawrence Erlbaum: Hillsdale, MI, USA, 1991; pp. $219-240$.

55. Harrison, A.G.; Treagust, D.F. Teaching with analogies: A case study in grade 10 optics. J. Res. Sci. Teach. 1993, 30, 1291-1307. [CrossRef]

56. Treagust, D.F. Enhancing students' understanding of science using analogies. In Teaching and Learning in Science; Hand, B., Prain, V., Eds.; Harcourt Brace: Sydney, Australia, 1993; pp. 44-62.

57. Schwarz, C.V.; Reiser, B.J.; Davis, E.A.; Kenyon, L.; Acher, A.; Fortus, D.; Shwartz, Y.; Hug, B.; Krajjcik, J. Developing a learning progression for scientific modeling: Making scientific modeling accessible and meaningful for learners. J. Res. Sci. Teach. 2009, 46, 632-654. [CrossRef] 
58. Harrison, A.G. Is there a scientific explanation for refraction of light? A review of textbook analogies. Austr. Sci. Teach. J. 1994, 40, 30-35.

59. Bindernagel, J.A.; Eilks, I. The roadmap approach to portray and develop chemistry teachers Pedagogical Content Knowledge concerning the particulate nature of matter. Chem. Educ. Res. Pract. 2009, 9, 77-85. [CrossRef]

60. Taber, K.S. Conceptual Resources for Learning Science: Issues of transience and grain-size in cognition and cognitive structure. Int. J. Sci. Educ. 2008, 30, 1027-1053. [CrossRef]

61. Eilks, I. Experiences and reflections about teaching atomic structure in a jigsaw classroom in lower secondary school chemistry lessons. J. Chem. Educ. 2005, 82, 313-320. [CrossRef]

C 2019 by the authors. Licensee MDPI, Basel, Switzerland. This article is an open access article distributed under the terms and conditions of the Creative Commons Attribution (CC BY) license (http://creativecommons.org/licenses/by/4.0/). 